\title{
ELECTRONIC MENU CARD FOR RESTAURANTS
}

\author{
Vikas Mullemwar ${ }^{1}$, Vaibhav Virdande ${ }^{2}$, Madhura Bannore ${ }^{3}$, Ashwini Awari ${ }^{4}$, Raviprakash Shriwas \\ ${ }^{1}$ J.D.I.E.T, Amravati University, Yavatmal, India \\ ${ }^{2}$ J.D.I.E.T, Amravati University, Yavatmal, India \\ ${ }^{3}$ J.D.I.E.T, Amravati University, Yavatmal, India \\ ${ }^{4}$ J.D.I.E.T, Amravati University, Yavatmal, India \\ ${ }^{5}$ J.D.I.E.T, Amravati University, Yavatmal, India
}

\begin{abstract}
In the restaurant business, 'presentation is half of the experience!'. Traditional paper menu cards are over all expensive, monotonous, difficult to maintain and over the period of time it lose its 'worthy appearance'. It is tedious to update paper menus with new prices, dishes and ingredients therefore to challenge all such obstacle and to enhance restaurant's guest experience and exquisiteness of the establishment Touchscreen Based electronic menu card is proposed. The other dimension to propose this new system is to reduce need of excess manpower and to eliminate excess time spend on giving manual order through waiter. The main focus is on increasing the usability and user friendliness of menu card with its simple navigation using GLCD and touch screen. The order can be placed by simply touching the available food menus. This automated menu card system gains many advantages over traditional menu ordering system.
\end{abstract}

Keywords - Electronic menu card, Touchscreen, GLCD, Restaurants

\section{INTRODUCTION}

Among the favorite premises restaurant is a place where people visits usually. While visiting such place people expects service that should satisfy them however it is common thing that customer complains when he doesn't feel the service is proper. That is the reason why hospitality and service have great important as well as impact on business transaction.

There are many reasons due to which the feeling of dissatisfaction arises in customer's mind which include being entertained late in terms of order taking by the waiter and meals serving. The time taken by waiter for taking order is very long, customer gets disappointed. In other case due to human error the wrong order is taken by customer and served to consumer.

In the recent past there has been evolution in ordering and serving system but still the results are not very much promising. With the advancement in communication technology the issue of being late entertained can be solved.

The proposed Touchscreen based menu card system has capacity to overcome time delays in traditional ordering system. Along with this it reduces the excess manpower need in restaurant business. As it is a gadget it doesn't need leave or vacation and thus work efficiently $24 \times 7$.

This paper highlights the drawbacks in the traditional menu ordering system compared to the proposed Touchscreen based menu card system.

\section{LITERATURE SURVEY}

\subsection{Other Available Ordering System}

Starting from the time when it was realised that hospitality, service and presentation have great impact on restaurant business transactions, many new ordering and serving scheme has been proposed up till now. These menu ordering techniques are as follows -

$>$ Paper based menu card

$>$ Self service food ordering KIOSK technology

$>$ QORDER

$>$ Computerized ordering system

\subsection{Paper Based Menu Card}

The existing system is paper based. This system is used mostly in restaurants. In this, menu cards offered to customers in restaurant are made of Paper, hard board. Waiters use notepad to write the order of customers. The records are stored on paper.

The working approach of this system is simple. Every time customer visits restaurant, occupy his table and selects his menu from available menu on paper menu card. When waiter arrives, he notes down order of customer in his notepad.

As with anything paper based, it is so easy for things to get damaged by water due to mishandling, or paper being lost due to fire or accidents or just generally lost. There is wastage of time, money, and paper. As menu card is made up of paper, if restaurant management wants to update menu list or prices, it 
leads to wastage of paper and it will require reprinting of all the menu cards. Also, in many cases for small change to be made in menu card it is not convenient to print all menu cards again. Simply saying that menu card once printed can't be changed. Moreover, after some days the menu card lost its worthy look. From the customer's point of view, this system is time consuming. As, one has to wait until the waiter comes to take the order, one has to call waiter number of times till he notices it, there can be misinterpretation while the waiter is writing your order on paper, and it might be possible that you are served with a wrong dish.

\subsection{Self Service Food Ordering KIOSK Technology}

In this technology, kiosk is free standing counter which is similar to self check out. It displays all menus including food items available and the payment mode.

Whenever, customer visits the restaurant he/she would navigate through the menu present on KIOSK display and select the food item available from list then pays the bill with available payment options. The customer will be given an order number. The order will be automatically routed to kitchen with physical connection. When the order is completed, order number is announced and displayed on screen then customer have to pick their food item from respective counter.

This system is mainly useful in fast-food restaurants as it saves time. Customers don't have to wait for waiter to take order. But in perspective of hospitality, this system is not proves itself worth. Imagine a customer visits restaurant with his family for dinner and have to pick his food from counter not even able to have a talk with his family. Person will have to wait for his order number to be announced and not able to concentrate in conversation. This is the biggest disadvantage of this system. Another thing is that during rush hour, customers will be queued for placing their orders. This doesn't seem comfortable even though it decreases order processing time.

\subsection{QORDER}

Other Advancement in menu ordering in hospitality industry is QORDER which is a portable ordering system. It is a portable handheld device that runs the complete QMP POS software on android device . It requires a WIFI to connect the remote corner. This system also involves waiter as in case of paper based menu card system. In this, the waiter no longer approaches the table with his notepad instead with the portable device known as QORDER, and then takes the order from customer. He then sends the order to kitchen for further processing. Once the customer finishes, the waiter prints the bill.

This technique is somewhat advanced because the portable QORDER device uses wireless technology to communicate with kitchen. However, the problem arises during rush hour when large number of people visits restaurant at the same time, the work load on waiter along with QORDER device increases.
Customers may have to wait for an arrival of waiter so that they can place their orders. Also if during the meal customer needs something then he have to call waiter. This ordering system is totally depends on manpower approaching customers to take order. Due to limited number of portable devices and manpower this system leads to failure. An error while taking order can still occur and the customer ends up with unsatisfactory experience.

Also important thing to be noted in this system is that the customer doesn't get fully customized order.

\subsection{Computerized Ordering System.}

This ordering system is somewhat same as KIOSK ordering system in aspect of order placing but differs in aspect of serving. Here food is served by waiters. But order is written on computer by restaurant staff.

When customer enters the restaurant, he has to orally tell his required food items from available menus to counter where staff member notes down his order. At the same time name of customer is also noted. When customer finishes his meal, at the counter he gets his bill and pays there.

This system looks advance due to use of computerized order but when large no of people visits restaurant, it becomes inconvenient to place order on the same system.

\section{PROPOSED SYSTEM}

The above mentioned traditional menu ordering and catering systems are time consuming and susceptible to human errors which can be reduced but can't be avoided. The problem with the self service ordering system is that self service restaurants are more popular in metro cities. So in smaller cities there are hardly any self service restaurants available. Many a times these self service systems take unreasonable amount of delays to deliver the order. The problem with the recently developed zigbee based system is its high cost and limited range.

Our aim is to develop a cost effective system which could work in small restaurants that are not willing to invest huge amount of money in these systems.

The newly suggested system is emphasised on increasing user friendly interface, simple navigation and low cost, increasing service range of wireless communication used and decreasing order processing time. This is done by efficient use of GLCD, Touchscreen, GSM module, and microcontroller.

\section{PROJECT SCOPE}

With the increasing need of automation in every field it becomes necessary to offer customer with an advance experience with satisfaction in restaurants. In current formal dining environment, large number of restaurant offers static menu i.e. paper menu card to convey available food items and waiters delivers order to kitchen staff. 
There is major scope in enhancing visual experience by replacing paper menu card with electronic menu card. To avoid delay in order, wireless communication can be used to replace waiter who manually deliver order to kitchen. Currently due to increased literacy, awareness of advance technology among people, they are crazy about latest technology and are eager to automate their routine tasks. So introducing new technology and approach in conventional food ordering system will lead to improved experience of customer.

\section{PROJECT DETAIL}

A Touchscreen along with Graphical LCD will be placed on each table. Now the GLCD will act as a menu card displaying all the items available in the restaurant. The available menus to be displayed on GLCD are programmed in microcontroller. According to customers requirement he or she will select menu item and quantity by touching on Touchscreen placed above the GLCD. Instantly the order will be transmitted to through microcontroller to receiving module in kitchen. GSM module is used for communication between transmitter on the table and receiver in cooking department in restaurant. Both transmitter and receiver contains microcontroller. The microcontroller which is at the receiver section takes the order which is displayed on LCD along with user table number.

On the Touchscreen, there will always be option for billing which will directly calculate billing amount for given order. Now when the customer demands for the bill, it is displayed on the GLCD screen at the user side. Whenever, customer touches the billing option, at bill paying counter his receipt will be printed with the respective table number printed.

This system will work as shown in figure 5.

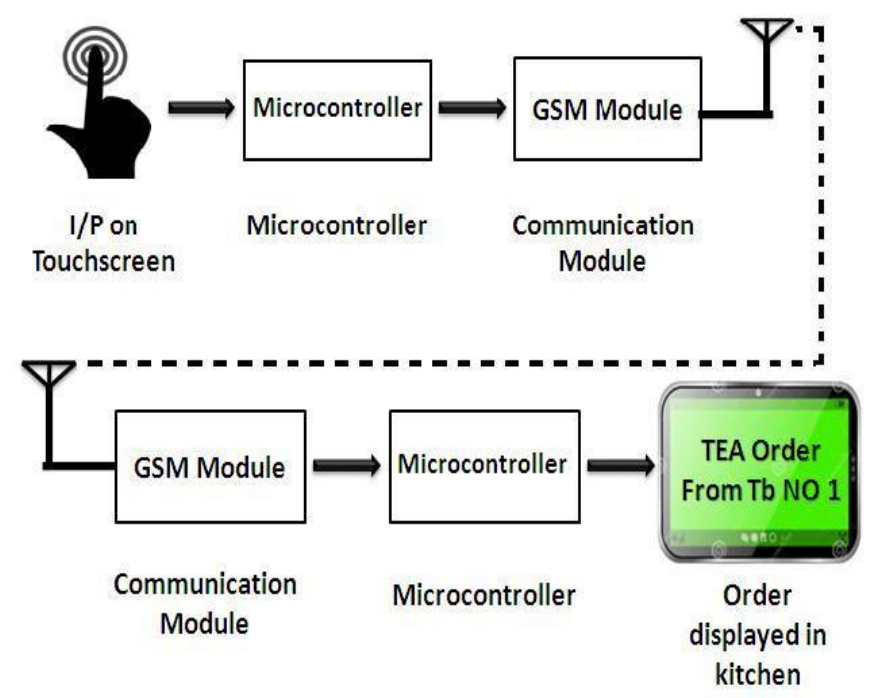

Fig.5 Overall working of proposed system

\subsection{Transmitter}

Transmitter block diagram for system is shown in fig 5(a). It contains Graphical LCD at one port of microcontroller. At ADC port of microcontroller, input form Touchscreen is connected. GSM module is connected to microcontroller. XTAL oscillator and regulated power supply is connected to microcontroller.

\subsection{Receiver}

Receiver block diagram for proposed system is shown in fig 5(b). In receiver simple LCD is connected at one port of microcontroller. GSM modules receive signals transmitted by transmitter and give it to microcontroller. Microcontroller displays it on LCD display connected at one of its port.

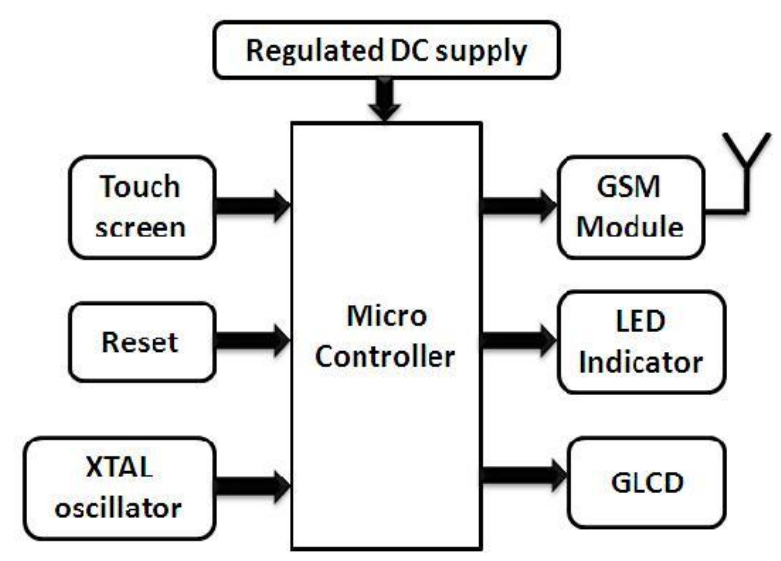

Fig.5 (a) Transmitter block diagram.

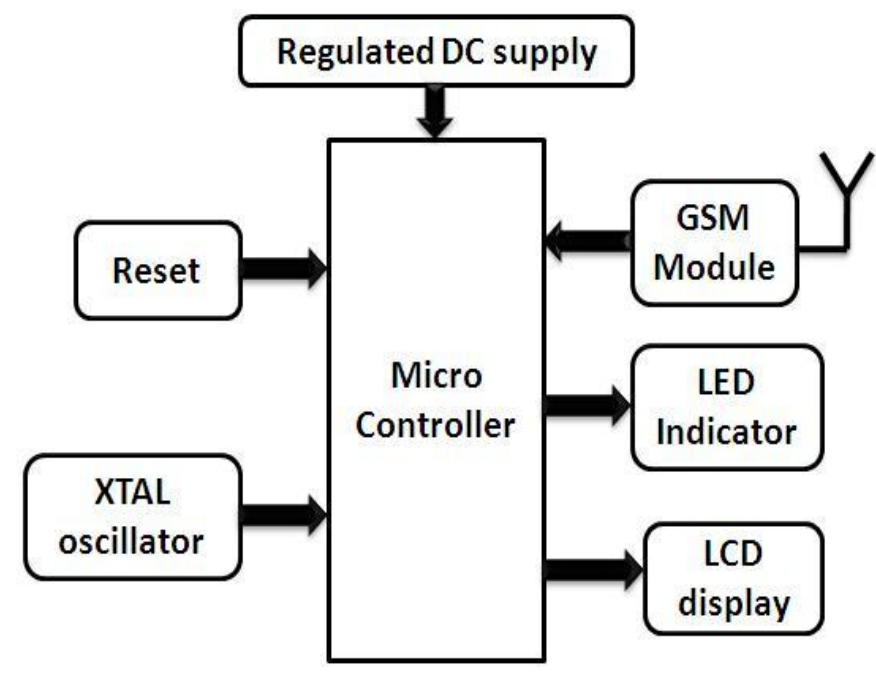

Fig.5 (b) Receiver block diagram. 


\section{SYSTEM DEVELOPMENT}

\subsection{Microcontroller}

The heart of the proposed system is the microcontroller which is used to control the activities of all other sections. Any Microcontroller which is cheap and readily available in the market having good programmable flash memory can be chosen. Newly developed microcontrollers with inbuilt ADC are preferable over traditional one as it eliminates need of external ADC IC in unit. Also there is no need to connect external memory if microcontroller has sufficient memory and circuit becomes sophisticated. Low power consuming microcontroller should be used to increase battery life of working unit.

\subsection{Touchscreen}

Touch screens are a clear sheet of plastic with tiny sensors that detect pressure from either a finger tip or a pointing device. When these sensors are pressed, they perform, they perform the functions found with the traditional mouse; single click, double click and drag. A software utility needs to be installed on the computer hard drive to further customize the different settings. Touch screens are great for the cause and effect and software applications that require direct select.

Depending on screen technologies used, Touch screens are of following types

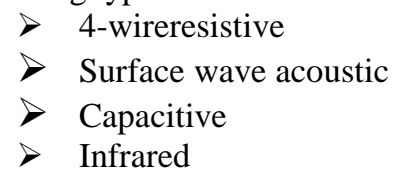

In proposed system the only functionality of Touchscreen that will be needed is single click or selecting the menu. As the Touchscreen is to be used in public environment it should have properties like high durability, less susceptible to contaminants, scratch resistance. In addition it should be transparent enough to visualize menu, it should have better response time and stability. Resistive touch screen technology possesses many advantages over other alternative touch screen. Highly durable, resistive touch screens are less susceptible to contaminants that easily infect acoustic wave touch screens.

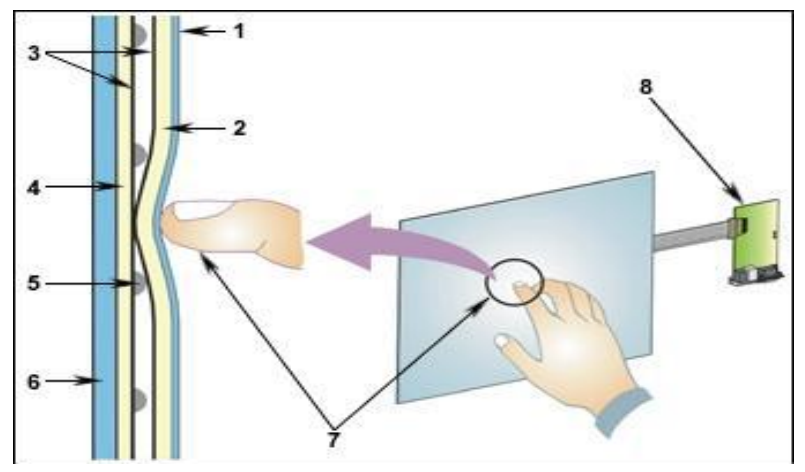

Fig 6(b) Touchscreen working

\subsection{Graphical LCD}

The 128*64 pixels graphic LCD provides the user a simple serial interface to full range of control. Besides writing text, serial graphic LCD allows the user to draw the circle \& boxes, sector reset, individual pixel, erase specific blocks of display, control the back light $\&$ adjust the baud rate.

\subsection{GSM Module}

GSM module is proposed to be used as means of wireless communication in proposed system. Its key attributes like less cost, quality performance, high range, reliability are advantageous over zigbee communication which was used in some previous menu ordering systems. Zigbee has very limited range of about 1 to $75+$ meters whereas GSM has range of 1000+ meters. GSM is also better choice over RF communication because RF communication has disadvantage that when more than 3 to $4 \mathrm{RF}$ modules are serving in same area , none of them works.

\section{SOFTWARE DEVELOPMENT}

For software development either assembly language or embedded $\mathrm{C}$ language can be used. The flow chart used for the development of software is shown in the figure.

\subsection{Transmitter Section Flow Chart}

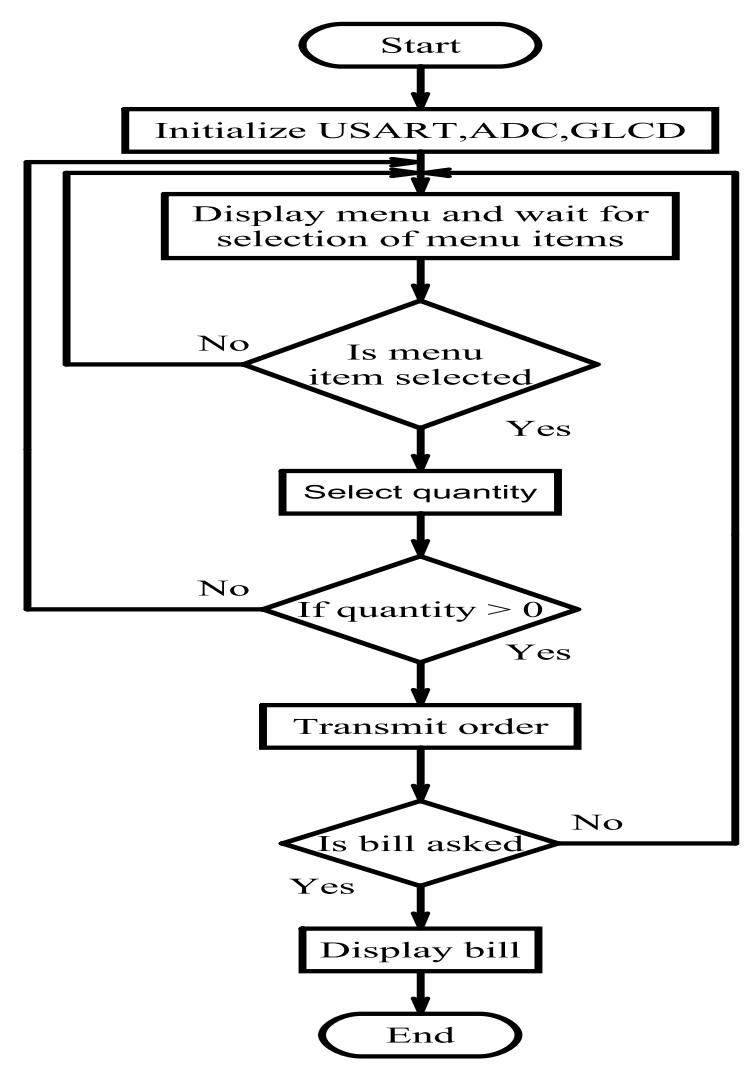

Fig 7(a) Transmitter flowchart 
The USART, GLCD and ADC must be initialized in the beginning. Menu is displayed on the GLCD and then the program waits for the selection of menu item. If the menu is selected and the quantity is greater than 0 than the order is transmitted to the ordering department. And if the user asks for the bill then the bill is displayed on the screen.

\subsection{Receiver Section Flow Chart}

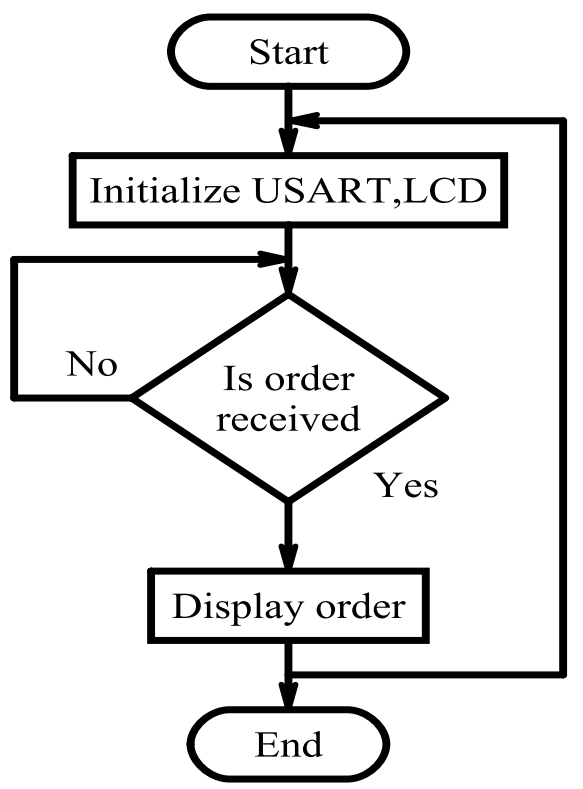

Fig 7(b) Receiver flowchart

On the receiver side only USART and LCD modules are initialized. If the order is received than it is displayed on LCD along with the table number.

\section{COMPARISON TO EXISTING SYSTEMS}

The proposed system when implemented will overcome disadvantages caused in other previous ordering system. There are many differences in previous systems and proposed system which can be given by comparison below.

Table 1 Comparison to existing systems

\begin{tabular}{|l|c|c|c|c|}
\hline & $\begin{array}{l}\text { Paper } \\
\text { menu } \\
\text { card }\end{array}$ & $\begin{array}{l}\text { KIOSK } \\
\text { Technolo } \\
\text { gy }\end{array}$ & $\begin{array}{l}\text { QORDER } \\
\text { system }\end{array}$ & $\begin{array}{l}\text { Touchscreen } \\
\text { based menu } \\
\text { card (GSM) }\end{array}$ \\
\hline $\begin{array}{l}\text { Wireless } \\
\text { network }\end{array}$ & No & No & Yes & Yes \\
\hline Touchscreen & No & Yes & Yes & Yes \\
\hline $\begin{array}{l}\text { Dependency } \\
\text { on waiter }\end{array}$ & High & Less & High & Less \\
\hline $\begin{array}{l}\text { Customized } \\
\text { order }\end{array}$ & No & Yes & No & Yes \\
\hline Order & High & High & High & Less \\
\hline
\end{tabular}

\begin{tabular}{|l|l|l|l|l|}
\hline $\begin{array}{l}\text { processing } \\
\text { time }\end{array}$ & & & & \\
\hline $\begin{array}{l}\text { Chance of } \\
\text { human error }\end{array}$ & High & Less & High & Less \\
\hline
\end{tabular}

\section{CONCLUSIONS AND FUTURE SCOPE}

Such kind of systems can prove worthy in transforming the whole catering industry. The proposed system will help in reducing the number of staffs used in the restaurants hence will help in considerably reducing cost of restaurant management. It will also minimize manual service given by waiters and serving staff, thus eliminating the human mistakes. It can also help in reducing child labor problem, which is a huge problem in countries like India.

Many improvements can be done in the proposed system like the resistive touchscreen can be replaced by more responsive capacitive touchscreen. RF module which is used for communication purpose starts to malfunction as more and more $\mathrm{RF}$ modules are used. This problem can be addressed by using costlier communication technologies like zigbee technology.

\section{REFERENCES}

[1]. Ashutosh Bhargave, Niranjan Jadhav, Apurva Joshi, Prachi Oke, Prof. S.R. Lahane, "Digital Ordering System For Restaurant Using Android", International Journal of Scientific and Research Publications, Vol. 3, Issue 4, April 2013.

[2]. Shweta S. Tanpure, Priyanka R. Shidankar, Madhura M. Joshi, "Automated Food Ordering System With Real-Time Customer Feedback", International Journal of Advanced Research in Computer Science and Software Engineering, Volume 3, Issue 2, February 2013.

[3]. System level solutions Lab manual, a study on Touch Screen by John J Rove.

[4]. V. Sridhar," Image based password authentication for illiterates with Touchscreen", International Journal of Science, Engineering and Technology Research (IJSETR) Volume 1, Issue 3, September 2012.

[5]. Snehal S. Dambhare, Mangesh A. Parjane, Dhananjay M. Deore," Touch Screen based menu ordering and displaying system for restaurants", International Journal of Computer Engineering and Technology Volume 3, Issue 2, JulySeptember (2012), pp. 297-30.

[6]. V. Swapna, M. Firdouse Ali Khan, "Design and Implementation of Ordering System for Restaurants", International Journal of Engineering Research \& Technology (IJERT), Vol. 1, Issue 10, December 2012. 